\title{
Amino-Terminal proCNP: A Putative Marker of Cartilage Activity in Postnatal Growth
}

\author{
TIMOTHY C.R. PRICKETT, ADRIENNE M. LYNN, GRAHAM K. BARRELL, BRIAN A. DARLOW, \\ VICKY A. CAMERON, ERIC A. ESPINER, A. MARK RICHARDS, AND TIMOTHY G. YANDLE \\ Department of Medicine [T.C.R.P., VAC., E.A.E., A.M.R., T.G.Y.], Christchurch School of Medicine and \\ Health Sciences, Christchurch 8015, New Zealand; Department of Pediatrics [A.M.L., B.A.D.], \\ Christchurch Hospital, Christchurch 8020, New Zealand; and Agricultural and Life Sciences Division
}

[G.K.B.], Lincoln University, Christchurch 8150, New Zealand

\begin{abstract}
Recent evidence from rodents and humans shows that C-type natriuretic peptide (CNP) plays an essential role in endochondral bone growth. We recently identified a stable product of proCNP, amino-terminal proCNP (NT-proCNP), which unlike CNP is readily measurable in human and ovine plasma. Hypothesizing that plasma NT-proCNP concentrations reflect in part CNP synthesis within growth plates of rapidly growing cartilage, we studied levels of CNP forms in both children and lambs and related these to age, growth velocity, and biochemical markers of bone turnover. Plasma NT-proCNP levels were elevated at birth and fell progressively with age. Significant associations between plasma NT-proCNP and height velocity, alkaline phosphatase, and type 1 collagen $\mathrm{C}$ telopeptide were identified in children (aged 5-18 y). In longitudinal animal studies, elevated plasma concentration of NT-proCNP in 1-wk-old lambs fell progressively to mature adult levels at age $27 \mathrm{wk}$. Plasma NT-proCNP
\end{abstract}

\section{ABSTRACT}

showed a highly significant association with alkaline phosphatase and metacarpal growth velocity. Glucocorticoids, a treatment known to inhibit cartilage proliferation, reduced metacarpal growth elongation in 4-wk-old lambs and markedly lowered circulating NT-proCNP levels during the treatment period. In summary, NT-proCNP levels in blood show a strong association with growth velocity and markers of bone formation and may well serve as a useful marker of growth plate activity in humans and other mammals. (Pediatr Res 58: 334-340, 2005)
Abbreviations
ALL, acute lymphatic leukemia
ALP, alkaline phosphatase
CNP, C-type natriuretic peptide
$\mathrm{CV}$, coefficients of variation
NT-proCNP, amino-terminal pro C-type natriuretic peptide

Skeletal growth results from a coordinated sequence of events involving proliferation and hypertrophy of chondrocytes within growth plates of long bones and deposition of intercellular matrix (1). Regulation of this process (endochondral growth) is complex and dependent on numerous paracrine and endocrine factors that variably modulate growth in utero and during the postnatal growing period. Despite increasing knowledge of the importance of paracrine factors, including bone morphogenetic proteins, Indian hedgehog, fibroblast growth factor, and PTH-related peptide, none of these has yet been used to assess growth plate activity in the clinical setting.

Atrial (ANP), B-type (BNP), and C-type natriuretic peptides (CNP), each the product of a separate gene, constitute a family

Received June 29, 2004; accepted November 24, 2004.

Correspondence: Eric A. Espiner, M.D., Department of Medicine, Christchurch School of Medicine and Health Sciences, P.O. Box 4345, Christchurch 8015, New Zealand; e-mail: eric.espiner@chmeds.ac.nz.

This work was supported by a grant from the Health Research Council of New Zealand and the Lotteries Board of New Zealand.

DOI: 10.1203/01.PDR.0000169964.66260.4B of structurally related peptides that regulate blood pressure and volume homeostasis (2). CNP, the most conserved across species of the three hormones, in contrast to ANP and BNP is not readily detected in blood, and circulating CNP has minimal natriuretic or vasodepressor activity in humans (3). Acting via its specific guanylyl cyclase receptor NPR-B (4), CNP has antiproliferative actions in vascular tissue (5), which may serve to regulate vascular remodeling and regeneration (6). Whereas the role of CNP in cardiovascular health is still unclear, several recent lines of evidence indicate that CNP plays an essential part in endochondral growth. CNP transcripts and their receptor NPR-B are expressed in chondrocytes of growth plates (7), and the addition of CNP stimulates both proliferative and hypertrophic zones, elongating bone explants in tissue culture (8). Furthermore, disruption of the CNP gene in mice yields a dwarfed phenotype and reduced chondrocyte proliferation, which can be rescued by targeted re-expression of the gene (9). That CNP is also essential to endochondral growth in humans was documented recently by the finding that loss-of-function mutations in NPR-B cause the profoundly dwarfed phenotype 
of acromesomelic dysplasia, Maroteaux type (10). Taken together, these findings confirm that CNP gene expression and action are important regulators of skeletal growth in mammals, including humans.

In light of similar patterns of processing of proANP and proBNP yielding bioactive carboxy-terminal and the (inactive) amino-terminal forms [NT-proANP (11) and NT-proBNP (12), respectively], we sought and successfully identified (13) a stable product of the CNP gene, amino-terminal proCNP (NTproCNP), which unlike CNP is readily measurable in human plasma. Hypothesizing that plasma NT-proCNP concentration reflects in part CNP synthesis within growth plates of rapidly growing cartilage, we studied levels of CNP forms in both children and growing lambs and related these to age and growth velocity. Here we report for the first time that NTproCNP levels in plasma are inversely related to age in both humans and sheep and correlate with growth velocity and markers of bone turnover before and after glucocorticoid administration, a treatment that is known to inhibit chondrocyte proliferation and linear growth.

\section{METHODS}

Adults. Blood samples for measurement of CNP and NT-proCNP were drawn from 16 healthy adult volunteers (aged 20-60 y) and 101 normal healthy adults (aged 50-80 y) who were recruited by random selection from the local electoral roll.

Children. Venous umbilical cord plasma was obtained from five full-term and eight premature $(<32 \mathrm{wk}$ gestation) deliveries. To define age- and growth-related changes in plasma CNP forms, we recruited an additional 60 children (33 female, 27 male), aged 5-18 y, from hospital outpatient clinics. All had normal renal function, and none showed cardiac abnormalities. Reasons for clinic attendance included monitoring of growth and development (32 patients), obesity (five patients), adrenal disorder (four patients), chronic inflammatory states (five patients), and history of oncologic disease (nine patients). Two of the last group had recently commenced chemotherapy and high-dose glucocorticoids for acute lymphoblastic leukemia (ALL) 1 wk before study. Four of the remaining 58 children had also received glucocorticoids (three physiologic replacement doses for adrenal insufficiency and one on a reducing dose of prednisone $10-20 \mathrm{mg}$ daily for dermatomyositis). Of the total group $(n=60), 21$ were receiving no medication at the time of study. In all recruited children, height (Harpenden Stadiometer) and weight were measured and blood was drawn on the same day (between 1300 and 1600) for CNP forms, alkaline phosphatase (ALP), and type 1 collagen $C$ telopeptide. Using heights measured at an interval of at least $3 \mathrm{mo}$ and within $6 \mathrm{mo}$ of blood sampling, it was possible to determine concurrent growth velocity in 23 of the 60 children. All studies were approved by the Canterbury Ethics Committee, and informed written consent was given by all participants or their parents, as appropriate.

Effect of age in sheep. Twelve sets of healthy mixed-sex Coopworth twin lambs were studied for a period of 6 mo. Lambs and mothers were maintained on pasture until weaning at $12 \mathrm{wk}$. From $1 \mathrm{wk}$ of age, lambs $(n=24)$ were weighed, the left metacarpal length was measured (vernier calliper), and jugular blood was drawn for CNP forms and ALP at intervals of 2 wk.

Effects of glucocorticoids. Acute effects of dexamethasone in sheep. The short-term effects of dexamethasone on CNP forms and ALP were compared in lambs and adult sheep. Eight Coopworth ewe lambs (aged 15 wk) and eight adult Coopworth ewes (aged $>4$ y) received dexamethasone $(125 \mu \mathrm{g} / \mathrm{kg})$ s.c. twice daily for $4 \mathrm{~d}$. Jugular-vein blood samples were collected at 0900 immediately before injections as well as during the 2-d run-in and run-out periods of study.

Effects of dexamethasone on growth velocity in sheep. For studying changes in both CNP forms and growth, 16 ewe lambs (aged 4 wk) were randomly allocated to receive dexamethasone $(125 \mu \mathrm{g} / \mathrm{kg}$ s.c. twice daily; $n=$ 8 ) or control ( $0.9 \%$ saline solution s.c. twice daily; $n=8)$ for a period of $15 \mathrm{~d}$. Commencing $6 \mathrm{~d}$ before and at intervals of 1-3 d during and after treatment, jugular-vein blood was drawn at 0900 (just before any injections) for analysis of CNP forms and ALP. All animals were weighed and the left metacarpal length was measured (vernier calliper) at intervals of 3-6 d throughout the study. All animal studies were approved by the Lincoln University Animal Ethics Committee.

Plasma assays. Blood samples were collected into chilled standard blood collection tubes that contained EDTA $(7.5 \mathrm{mg} / \mathrm{mL}$; Vacutainer, Becton Dickinson, Plymouth, UK) and centrifuged at $4{ }^{\circ} \mathrm{C}$, and plasma was stored at $-20^{\circ} \mathrm{C}$ before analysis for CNP, NT-proCNP, and ALP (Aeroset analyser; Abbott Laboratories, Abbot Park, IL). Type 1 collagen C-telopeptide ( $\beta$-CrossLaps) was measured using an Elecsys 2010 analyser (Roche Diagnostics, Mannheim, Germany). All plasma samples from individual sheep were measured in the one assay.

RIA for amino-terminal proCNP. NT-proCNP was assayed as previously described (13) except that a more sensitive primary rabbit antiserum (J39) raised against NT-proCNP (1-15) was used. Peptide standards were made from synthetic human proCNP (1-19), taking into account the purity data supplied (Chiron Technologies Pty Ltd, Melbourne, Australia). This assay has a detection limit of $1 \mathrm{pmol} / \mathrm{L}$ (2 SD from zero) and an EC50 of 90 pmol/L. Withinand between-assay coefficients of variations (CVs) were 5.0 and $7.9 \%$, respectively, at $19 \mathrm{pmol} / \mathrm{L}$.

$\boldsymbol{R I A}$ for CNP22. CNP22 was assayed as previously described (14), except that the assay was preincubated with antisera for $22 \mathrm{~h}$ before the addition of ${ }^{125}$ I-labeled CNP $(5000 \mathrm{cpm})$ and incubated for an additional $24 \mathrm{~h}$ at $4{ }^{\circ} \mathrm{C}$.

Extraction of peptides from lamb growth plate cartilage. Immediately after the lambs were killed (captive bolt), lamb growth plate cartilage was dissected from proximal or distal ends of limb bones (tibia, metatarsal, or metacarpal), quickly frozen on dry ice, and stored at $-80^{\circ} \mathrm{C}$ before extraction. Frozen cartilaginous tissue $(0.5-1 \mathrm{~g})$ was diced, boiled, acidified with acetic acid, and homogenized before extraction on Sep-Pak C18 cartridges (Waters Corporation, Milford, MA) as previously described for ovine pituitary tissue (14). Extracts were resuspended in either assay buffer for RIA or $20 \% \mathrm{CH}_{3} \mathrm{CN}$ in $0.1 \%$ TFA before size exclusion (Toyo Soda G3000) HPLC. Fetal lamb tissue was obtained after a pregnant ewe was killed using sodium pentobarbital.

Statistical methods. Data are presented as mean \pm SEM where appropriate. $\mathrm{CVs}$ are presented as percentages and represent the root mean square of CVs from human and lamb serial measurements. $t$ test was used to analyze differences in hormone levels between adults and children. ANOVA with repeated measures was used to assess changes in biochemical and physical measurements in lambs using time, sex, and dexamethasone treatment as the independent variables. When significant changes were observed with ANOVA, Bonferroni post hoc analysis was used to detect differences from baseline values (day -2) and control time-matched data as appropriate. General linear models were used to test the associations (correlations) between variables using data obtained during weeks 1-19. These were used to test the pooled associations between variables within each lamb. Statistical significance was assumed at $p<0.05$.

\section{RESULTS}

Studies both in adult humans and in lambs showed that plasma levels of NT-proCNP varied little from day to day (CV on repeated sampling from eight lambs over $9 \mathrm{~d}$ was $9.3 \%$; range $4-14 \%)$. In healthy adult humans $(n=6)$, NT-proCNP levels drawn at 0900, 1200, 1300, and 1500 showed no significant difference and were not affected by a standard meal ingested at noon $(\mathrm{CV}=6.9 \%$; range $3-10 \%)$.

Effects of age on plasma CNP forms in humans. Plasma concentrations of NT-proCNP and CNP were measured in humans who ranged in age from 0 to $80 \mathrm{y}$. As shown in Fig. $1 A$, plasma NT-proCNP levels in children (5-18 y) were $>2$-fold those of adults $>20$ y (mean $46.6 \pm 1.7$ versus 19.2 $\pm 0.4 \mathrm{pmol} / \mathrm{L} ; p<0.001$ ). Plasma CNP levels were much lower than NT-proCNP levels and showed a small but significant difference between the two groups (mean $1.03 \pm 0.05$ versus $0.93 \pm 0.03 \mathrm{pmol} / \mathrm{L}$ in children and adults, respectively; $p=0.045)$. Two girls who had recently started on inductive chemotherapy and prednisone (45 and $70 \mathrm{mg} / \mathrm{day}$, respectively) for ALL had extremely low levels of NT-proCNP (9.4 $\mathrm{pmol} / \mathrm{L}$ at age 10 and $6.7 \mathrm{pmol} / \mathrm{L}$ at age $14 \mathrm{y}$, respectively; Fig. $1 A$ ), raising the possibility that high-dose glucocorticoids or chemotherapy suppresses CNP synthesis. 


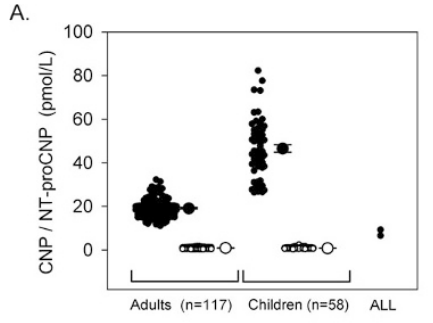

B.

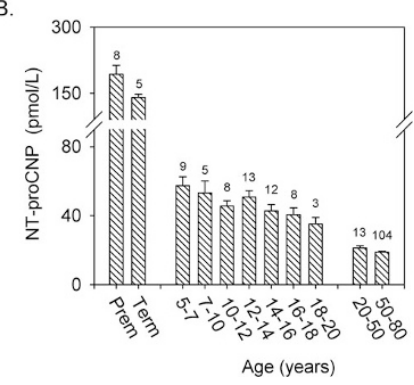

Figure 1. (A) Dot plot of NT-proCNP $(\bullet)$ and CNP $(\bigcirc)$ and mean \pm SEM bars in children (aged 5-18 y) compared with levels in healthy adult subjects (aged 20-80 y). Plasma levels of NT-proCNP in two children who received acute chemotherapy and high-dose glucocorticoids for ALL are also shown. (B) Plasma NT-proCNP levels (bars \pm SEM) stratified by age. Numerals above bars indicate numbers of subjects. Prem, premature ( $<32 \mathrm{wk})$ delivery; Term, full-term delivery.

Plasma NT-proCNP levels were elevated at birth and fell progressively with age (Fig. $1 B$ ). The trend for high levels in cord plasma in premature (mean $193 \pm 20 \mathrm{pmol} / \mathrm{L} ; n=8$ ) compared with term deliveries (mean $141 \pm 7 \mathrm{pmol} / \mathrm{L} ; n=5$ ) did not attain statistical significance $(p=0.07)$. As shown in Fig. $2 A$ and $B$, there was a significant positive association in the 5- to 18-y age group between height velocity and plasma NT-proCNP $(r=0.57, p=0.005)$ and between ALP (a marker
A.

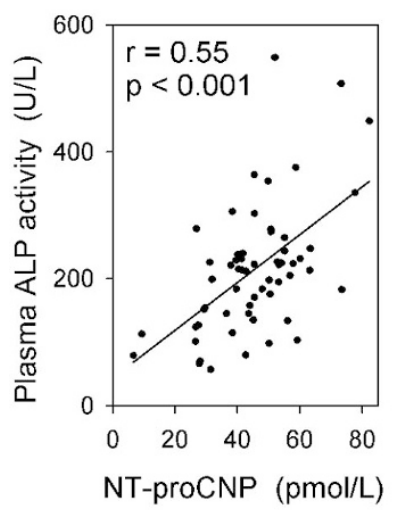

C.

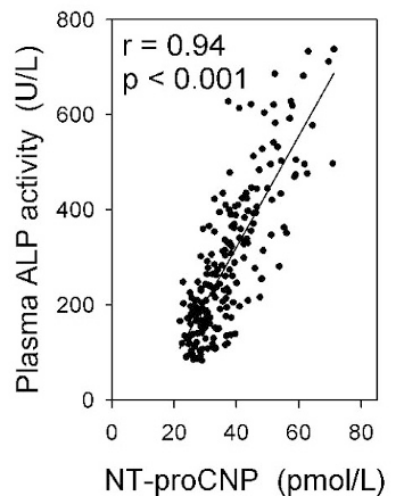

B.

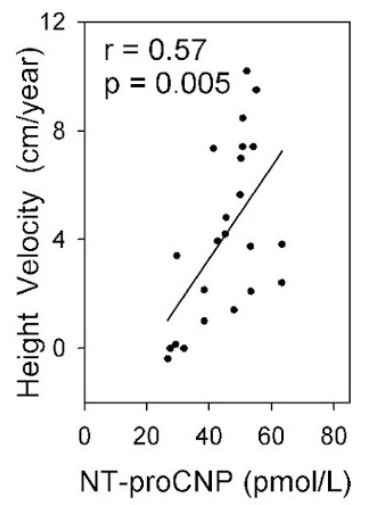

D.

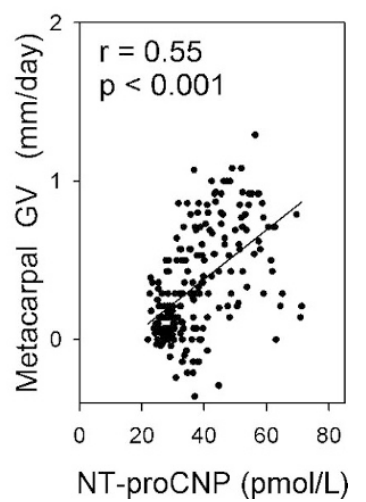

Figure 2. ( $A$ and $B$ ) Correlations between plasma NT-proCNP in children (aged 5-18 y) and plasma ALP activity $(A)$ and height velocity $(B)$. $(C$ and $D)$ Correlations between plasma NT-proCNP in growing lambs and plasma ALP activity $(C)$ and metacarpal growth velocity $(\mathrm{GV} ; D)$. of bone formation) and plasma NT-proCNP $(r=0.55, p<$ 0.001). The marker of bone resorption type 1 collagen $\mathrm{C}$ telopeptide was significantly correlated with NT-proCNP $(r=$ $0.33, p=0.013)$. Both type 1 collagen C telopeptide $(r=0.52$, $p=0.012)$ and $\operatorname{ALP}(r=0.65, p<0.001)$ were significantly correlated with height velocity and each other $(r=0.67, p<$ $0.001)$.

Changes in plasma CNP forms, ALP, and metacarpal growth in growing lambs. Sequential changes in plasma NTproCNP, CNP, and ALP in growing lambs from age 1-30 wk are shown in Fig. 3. Levels of all three analytes declined progressively with time $(p<0.001$ for each) to achieve more stable levels at 15-30 wk. Small increments in NT-proCNP, CNP, and ALP (as well as metacarpal growth velocity; data not shown) occurred in both sexes at 20-25 wk (Fig. 3). A statistically significant effect of sex on levels of NT-proCNP (but not CNP or ALP) was identified with higher mean NTproCNP concentrations in ram lambs $(F=8.2, p=0.015)$. Molar concentrations of NT-proCNP were 10- to 15 -fold those of CNP throughout the study period.

As shown in Fig. $2 C$ and $D$, there was a highly significant positive association of NT-proCNP with ALP $(r=0.94, p<$ 0.001 ; Fig. $2 C)$ and with metacarpal growth velocity $(r=0.55$, $p<0.001$; Fig. $2 D$ ). Similarly, there was a positive association of metacarpal growth velocity with CNP $(r=0.48, p<0.001)$ and with ALP $(r=0.57, p<0.001)$.

Effects of glucocorticoids. The finding of strikingly low levels of NT-proCNP in two children who received inductive chemotherapy and high-dose glucocorticoids prompted study of the effects of dexamethasone on CNP forms and growth velocity in sheep. As shown in Fig. 4, dexamethasone $0.25 \mathrm{mg}$ $\cdot \mathrm{kg}^{-1} \cdot \mathrm{d}^{-1}$ for $4 \mathrm{~d}$ markedly reduced plasma NT-proCNP and ALP in lambs but less so in adult sheep. This differential response to dexamethasone was highly significant for both NT-proCNP $(F=5.4, p<0.001)$ and ALP $(F=4.1, p=$ 0.002). After $48 \mathrm{~h}$ of dexamethasone treatment, plasma NTproCNP in lambs fell $30.8 \pm 3.5 \%$ from basal compared with $17.7 \pm 2.7 \%$ in adult sheep. Both the onset and the offset of dexamethasone's action on NT-proCNP preceded that of ALP (Fig. 4).

To study a possible linkage between changes in CNP and growth velocity, we undertook a more prolonged study in younger growing lambs. As shown in Fig. 5, dexamethasone $0.25 \mathrm{mg} \cdot \mathrm{kg}^{-1} \cdot \mathrm{d}^{-1}$ for $15 \mathrm{~d}$ in 4 -wk-old lambs was associated with a highly significant fall in NT-proCNP within $24 \mathrm{~h}$ of starting treatment $(F=7.5, p<0.001)$ and was sustained
A.

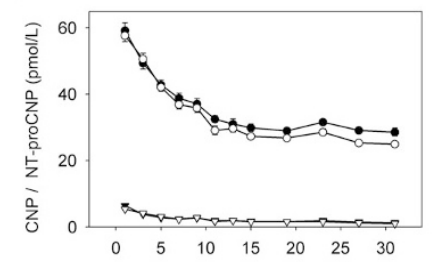

B.

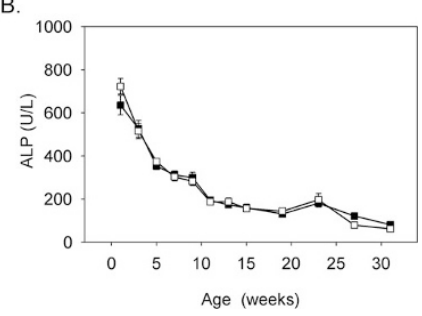

Figure 3. Plasma levels of NT-proCNP (circles) CNP (triangles; $A$ ) and ALP activity (squares; $B$ ) in lambs from age $1-30 \mathrm{wk}$. Rams $(n=12$, filled symbols); ewes ( $n=12$, open symbols). Values are mean \pm SEM. 
A.
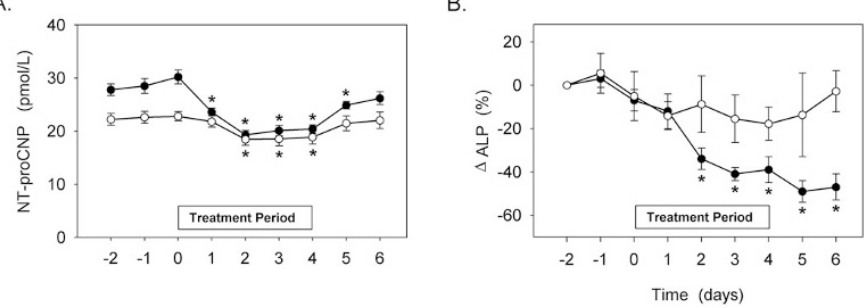

Figure 4. Effect of $4 \mathrm{~d}$ of treatment with dexamethasone $\left(0.25 \mathrm{mg} \cdot \mathrm{kg}^{-1}\right.$. $\left.\mathrm{d}^{-1}\right)$ in 12-wk-old ewe lambs $(O ; n=8)$ and ewe adults $(\bigcirc ; n=8)$ on plasma NT-proCNP $(A)$ and change $(\Delta ; B)$ in plasma ALP activity. Values are mean \pm SEM. Significant differences from baseline values (day -2$)$ are indicated by asterisks $(* p<0.05)$.

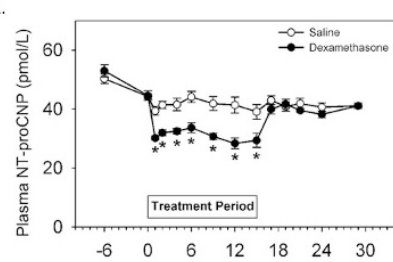

C

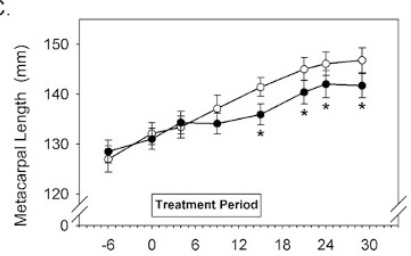

B.

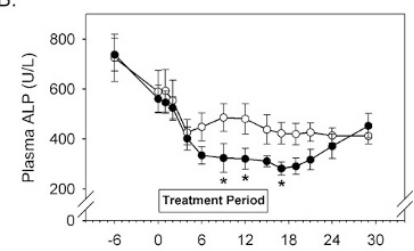

D.

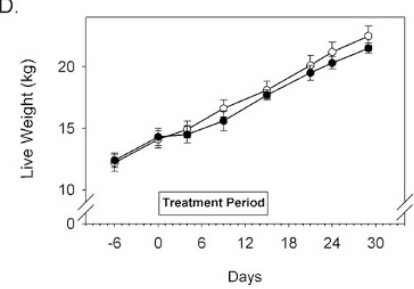

Figure 5. Effect of dexamethasone $(0 ; n=8)$ or saline control $(\bigcirc ; n=8)$, administered to 4-wk-old ewe lambs for $15 \mathrm{~d}$, on plasma NT-proCNP $(A)$, plasma ALP activity $(B)$, metacarpal length $(C)$, and body weight $(D)$. Values are mean \pm SEM. Significant differences between dexamethasone and saline control time-matched data are indicated by asterisks $\left(*^{*} p<0.05\right)$.

throughout the period of dexamethasone treatment. Similar changes occurred in plasma CNP $(F=9.2, p<0.001$; data not shown). Both analytes returned to control levels within $24 \mathrm{~h}$ of cessation of treatment. Whereas plasma ALP activity also decreased during the treatment period $(F=1.9, p=0.029$; Fig. $5 B)$, the onset and the offset of response in ALP to dexamethasone was delayed when compared with that of NTproCNP. Dexamethasone treatment was associated with a pronounced decrease in metacarpal elongation $(F=7.0, p<$ 0.001, Fig. 5C), which abated after restoration of NT-proCNP levels.

Compared with saline-treated lambs, a small but significant effect of dexamethasone on body weight $(F=4.4, p<0.001$; Fig. $5 D$ ) was observed. However, in contrast to metacarpal elongation, differences between treatment groups at cessation of dexamethasone treatment (day 15) were not significantly different.

NT-proCNP in fetal and lamb growth plates. As shown in Fig. 6, NT-proCNP was identified in extracts of tibial growth plate tissue excised from the fetal lamb (18 wk gestation). When subjected to SE-HPLC/RIA, a major peak of immunoreactivity eluted across fractions 29 and 30 (molecular mass $\sim 5$ $\mathrm{kD}$ ). There was no evidence of the prohormone (proCNP $\mathrm{Mr}=$ $10.9 \mathrm{kD})$.

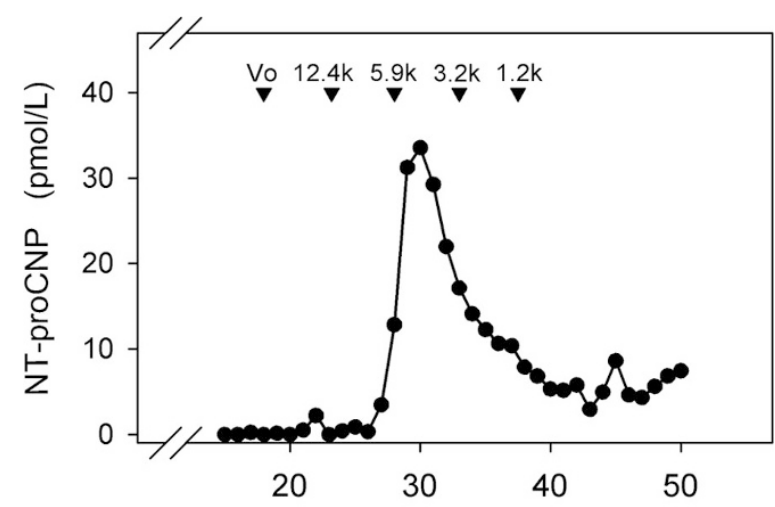

Fraction No.

Figure 6. NT-proCNP SE-HPLC immunoreactive profile of growth plate cartilage extract obtained from a fetal lamb tibia (gestation $\sim 18 \mathrm{wk}$ ). Column void volume $\left(\mathrm{V}_{\mathrm{o}}\right)$ and elution positions of molecular markers are shown by arrows.

The concentrations of CNP and NT-proCNP in tissue extracts of limb bone cartilaginous growth plates that were removed from 12-wk-old lambs $(n=4)$ are shown in Table 1 together with blood plasma concentration of these peptides at the time of growth plate collection. Excepting marrow tissue, the concentration $(\mathrm{fmol} / \mathrm{g})$ of growth plate extracts exceeded the corresponding level in plasma. Ratios of NT-proCNP to CNP (mean 4; range 1-10) in growth plate tissues were lower than the ratio found in plasma (mean 23; range 21-25).

\section{DISCUSSION}

Our results, in showing a strong association of plasma NT-proCNP with growth velocity and markers of bone formation in growing lambs and children, provide support for the hypothesis that plasma NT-proCNP may serve as a marker of growth plate cartilage activity. In keeping with increasing evidence of CNP's role in lengthening the appendicular and axial skeleton (15), the findings now call for prospective studies on the use of plasma NT-proCNP measurements in predicting growth and skeletal development in humans.

As reported previously, plasma concentrations of the biologically active (carboxyterminal) forms of proCNP (CNP 53 and CNP 22) are low in both humans and sheep, close to the

Table 1. Growth plate tissue, marrow and plasma levels of NT-proCNP, CNP and ratios in 12 week-old ewe lambs (mean + $S E M, \mathrm{n}=4)$

\begin{tabular}{lccc}
\hline \multicolumn{1}{c}{ Tissue } & $\begin{array}{c}\text { NT-proCNP } \\
\text { (fmol/g) }\end{array}$ & $\begin{array}{c}\text { CNP } \\
\text { (fmol/g) }\end{array}$ & $\begin{array}{c}\text { Ratio } \\
\text { NT-proCNP/CNP }\end{array}$ \\
\hline Tibia & & & \\
$\quad$ Proximal & $72 \pm 13$ & $11 \pm 3$ & $6.9 \pm 1.2$ \\
$\quad$ Distal & $48 \pm 23$ & $14 \pm 7$ & $3.4 \pm 0.7$ \\
Metatarsal & & & \\
$\quad$ Proximal & $114 \pm 28$ & $57 \pm 29$ & $3.2 \pm 1.0$ \\
$\quad$ Distal & $73 \pm 31$ & $30 \pm 17$ & $2.3 \pm 0.6$ \\
Metacarpal & & & \\
$\quad$ Proximal & $89 \pm 10$ & $33 \pm 3$ & $2.7 \pm 0.1$ \\
$\quad$ Distal & $84 \pm 27$ & $29 \pm 10$ & $2.7 \pm 0.5$ \\
Marrow (metatarsal) & $23 \pm 2$ & $6.6 \pm 0.2$ & $3.4 \pm 0.2$ \\
Plasma (pmol/L) & $32 \pm 1$ & $1.8 \pm 0.1$ & $22.8 \pm 0.8$ \\
\hline
\end{tabular}


level of the assay detection, and show relatively small changes in pathologic states $(2,16)$. By contrast, NT-proCNP is readily detected and circulates at levels 10- to 50-fold those of CNP. We show here that both NT-proCNP and CNP (despite the low levels) vary inversely with age during the growing period. Using a human chondrosarcoma line, it was shown recently that processing of proCNP (yielding amino-terminal proCNP 1-50 and CNP 53) occurs intracellularly (17). Assuming that equimolar concentrations of amino- and carboxyterminal forms are secreted from cells, rapid uptake and degradation of CNP 53 (or CNP 22) by the natriuretic peptide clearance receptor (NPR-C) and/or hydrolysis by tissue neutral endopeptidase (NEP) (18) will limit access of CNP (but presumably not NT-proCNP) to the circulation. In addition, both degradation pathways will shorten the half-life of CNP in plasma (3). Consistent with this view is the higher ratio of NT-proCNP/ CNP in plasma compared with those that we found in growth plate cartilage (Table 1). This differential vulnerability of CNP forms to degradation by NPR-C and NEP, both of which are expressed in cartilage and skeletal tissue $(19,20)$, increasing the likelihood that plasma NT-proCNP will better reflect CNP synthesis within tissues provided that renal function is normal (16). To obtain more direct evidence that growth plate cartilage levels were enriched (compared with jugular venous plasma), we sampled a variety of growth plate cartilage tissue extracts in 12-wkold lambs. Although tissue levels were higher than found in plasma, it should be noted that this study was undertaken at a time when plasma levels were close to mature (adult) levels and when linear growth was almost complete. Further studies are planned in younger, rapidly growing lambs to define the linkage, if any, among levels of NT-proCNP in growth plates, chondrocyte immunohistochemistry, and growth velocity. Presumably a number of tissues contribute to circulating levels of NT-proCNP. CNP gene expression in rodents is reported in a variety of extraskeletal tissues, including brain, reproductive tissues, lung, and vascular endothelium (21-24). All of these tissues are potential sources of circulating NT-proCNP. However, our finding of strong associations of blood levels with growth velocity and markers of bone growth, together with the close temporal relationship of NTproCNP with changes in metacarpal growth and ALP during glucocorticoid treatment, point to an important contribution from growing cartilage. Although we cannot exclude a placental contribution to the very high levels of NT-proCNP found in cord plasma, previous work (25) showing lower molar concentrations of NT-proCNP in placental tissues than in cord plasma and evidence that natriuretic peptides (ANP) do not cross the placenta (26) make this unlikely. It remains to be seen whether cartilage, bone, or other (possibly vascular) tissues contribute to the relatively stable levels of NT-proCNP that we observe in mature normal adults (humans) and sheep. However, the small fall in levels $(\sim 17 \%)$ in adult sheep during short-term dexamethasone treatment $\left(0.25 \mathrm{mg} \cdot \mathrm{kg}^{-1} \cdot \mathrm{d}^{-1}\right)$ is consistent with some sustained contribution from the skeleton even in the fully mature state.

Although the duration of linear growth is different in the two species ( 1.5 y in sheep, up to $18 \mathrm{y}$ in humans), the pattern of decrease in plasma NT-proCNP (from birth to maturity) seems to be similar and is consistent with the progressive decrease in hypertrophic and proliferative chondrocytes found in human studies (27). It is interesting that higher levels were noted in males [rams in current study and in humans (16)], in contrast to the consistently higher levels of ANP/BNP and related forms in females (28). Similar gender effects are reported for markers of collagen 1 (29) and collagen 3 (30) synthesis, which have been attributed to greater bone volumes in males. Our more recent analysis of cord plasma NT-proCNP in preterm and term infants $(n=23)$ shows a strong negative relationship of level with gestational age $(r=-0.49, p=0.015)$. Similar negative associations have been found for markers of collagen 1 and collagen 3 turnover with gestational age (30). These relationships are consistent with linkage of both cartilage activity and bone turnover with growth velocity, which is maximum in the human fetus during the third trimester and in the first year of postnatal life. A much more defined database is now required, relating NT-proCNP level to age and concurrent growth velocity throughout the growing period in normal children and in adolescents. Our study was not designed to examine changes in the peripubertal growth phase, which would require more frequent and focused sampling commencing at the onset of the pubertal growth surge. Although nothing is known of changes in CNP gene expression during this phase of growth, it is to be noted that small increments in NT-proCNP and ALP were found in both sexes at 20-25 wk in lambs. Conceivably, a short period of increased CNP synthesis within key growth plates underlies these changes. It is interesting that in rodent models of impaired CNP gene expression (9), as well as in loss of function mutations of the human NPR-B (10), linear growth impairment is not fully expressed until after birth. It remains to be seen whether plasma NT-proCNP levels during the first year of life in humans predict final adult height and whether cord plasma levels have an impact on growth rate or skeletal development as previously reported for IGF-1 (31) or calcium concentration (32).

The finding of very low levels of NT-proCNP (the lowest that we have observed in our laboratory) in two children who recently started on chemotherapy and high doses of glucocorticoids prompted study of dexamethasone's action in lambs and adult sheep. As expected from previous work showing glucocorticoid-induced inhibition of chondrocyte proliferation and differentiation (33), we noted prompt and significant decreases in both NT-proCNP and ALP with dexamethasone administration, effects that were greater in lambs than in mature adult sheep in keeping with the larger content of growth plate cartilage in lambs. That these changes are associated with linear growth inhibition was shown by a longer period of dexamethasone treatment in younger lambs. In both short- and long-term studies, the onset and the offset of dexamethasone's effect on NT-proCNP preceded that observed in ALP. Although plasma ALP in lambs is presumably sourced from osteoblasts and other tissues, as well as cartilage, this differential effect is consistent with actions of dexamethasone early in the cell cycle (e.g. on proliferating chondrocytes) with consequential (delayed) effects on the later maturing hypertrophic zone from which ALP (in cartilage) is largely sourced (34). It is to be noted that normal levels of plasma NT-proCNP were restored within $24 \mathrm{~h}$ after cessation of dexamethasone, whereas ALP did not attain "control" levels for an additional 
$9 \mathrm{~d}$, during which time the inhibitory effect on metacarpal lengthening had abated. The precise mechanism whereby glucocorticoids inhibit NT-proCNP was not addressed in our study. Possibly, levels fall as a consequence of depletion of proliferative chondrocytes (35) from which CNP is largely sourced (9). Although a classic glucocorticoid response sequence has not been identified in the CNP gene (36), inhibitory effects of glucocorticoids may be mediated by changes in transcriptional factors acting at the level of the CNP promoter. In this context, it is of note that in rat articular chondrocytes (37), the signalling pathway of TGF- $\beta$, a potent stimulus to CNP mRNA expression $(22,38)$, is blocked by dexamethasone. TGF- $\beta$ is known to up-regulate CNP expression through the transcriptional modulator TSC-22, which binds to GC-rich cis elements within the CNP promoter (38). Similar inhibitory effects of dexamethasone on TGF- $\beta$ synthesis (39) or signalling (40) have been described in other cell systems, raising the possibility that the growth arrest results in part from loss of CNP and its trophic action on chondrocytes (41) and on matrix synthesis (42). If proved, then such a mechanism of action could have important therapeutic implications, including the prospect of interventions that restore (42) or maintain (43) local levels of CNP within the growth plate and reduce the deleterious effects of glucocorticoids on the growing skeleton. The daily doses of glucocorticoid used here (approximately equivalent to $35-40 \mathrm{mg} / \mathrm{d}$ prednisone in a $30-\mathrm{kg}$ child) are less than the doses received by children with ALL $(45-75 \mathrm{mg} / \mathrm{d}$ prednisone). Chemotherapy also has the potential to inhibit chondrocyte proliferation and linear height (44) and also may have contributed to the profoundly low values observed in the two children. Clearly, the separate effects of glucocorticoid and chemotherapies at a range of doses are required to clarify the actions of these drugs.

Conclusions drawn from our findings need to be tempered in light of several limitations. Although the associations of plasma NT-proCNP with growth velocity and bone markers are strong, proof that levels truly reflect changes in growth plate activity requires further study, possibly using genetic models in which the expression of CNP within cartilage is rendered dysfunctional. Furthermore, it is well recognized that glucocorticoids have profound inhibitory effects on protein synthesis in many tissues, not just growth plate chondrocytes. Thus, it is possible that the changes that we observed reflect inhibition of CNP gene expression in several different tissues. Finally, our studies in growing children were necessarily limited in several respects: only a single value (cross-sectional study) was obtained in any one child; a range of different morbid states and treatments were represented in this study group (which did not include children in the postnatal to $5 \mathrm{y}$ age group), and the numbers of children in whom it was possible to calculate growth velocity was less than half the original study population. Despite these limitations, the findings drawn from cord blood samples and children in the 5- to 18-y group are consistent with those observed in healthy growing lambs.

Should future studies confirm that plasma NT-proCNP is largely sourced from cartilage in the developing skeleton, monitoring the level could be a valuable aid to predicting future growth potential as well as helpful in providing an early warning of impaired growth plate activity in patients who receive glucocorticoids or other agents that are known to affect growth adversely. Conceivably, genetic disorders of CNP synthesis and/or action may be identified by abnormality of plasma NT-proCNP once an age-related reference range is established and the contribution of other organ dysfunctions (e.g. renal impairment) is more fully defined. In conclusion, NT-proCNP levels in blood show a strong association with growth velocity and markers of bone formation and may well serve as a useful marker of cartilage growth plate activity and health.

Acknowledgments. We gratefully acknowledge the expert technical assistance of Dr. Chris Charles, Martin Wellby, Kathryn Wright, and John Dunnet in the animal studies.

\section{REFERENCES}

1. Kronenberg HM 2003 Developmental regulation of the growth plate. Nature 423:332-336

2. Espiner EA, Richards AM, Yandle TG, Nicholls MG 1995 Natriuretic hormones. Endocrinol Metab Clin North Am 24:481-509

3. Hunt PJ, Richards AM, Espiner EA, Nicholls MG, Yandle TG 1994 Bioactivity and metabolism of C-type natriuretic peptide in normal man. J Clin Endocrinol Metab 78:1428-1435

4. Koller KJ, Lowe DG, Bennett GL, Minamino N, Kangawa K, Matsuo H, Goeddel DV 1991 Selective activation of the B natriuretic peptide receptor by C-type natriuretic peptide (CNP). Science 252:120-123

5. Furuya M, Yoshida M, Hayashi Y, Ohnuma N, Minamino N, Kangawa K, Matsuo H 1991 C-type natriuretic peptide is a growth inhibitor of rat vascular smooth muscle cells. Biochem Biophys Res Commun 177:927-931

6. Yamahara K, Itoh H, Chun TH, Ogawa Y, Yamashita J, Sawada N, Fukunaga Y, Sone M, Yurugi-Kobayashi T, Miyashita K, Tsujimoto H, Kook H, Feil R, Garbers DL, Hofmann F, Nakao K 2003 Significance and therapeutic potential of the natriuretic peptides/cGMP/cGMP-dependent protein kinase pathway in vascular regeneration. Proc Natl Acad Sci USA 100:3404-3409

7. Hagiwara H, Sakaguchi H, Itakura M, Yoshimoto T, Furuya M, Tanaka S, Hirose S 1994 Autocrine regulation of rat chondrocyte proliferation by natriuretic peptide C and its receptor, natriuretic peptide receptor-B. J Biol Chem 269:10729-10733

8. Yasoda A, Ogawa Y, Suda M, Tamura N, Mori K, Sakuma Y, Chusho H, Shiota K, Tanaka K, Nakao K 1998 Natriuretic peptide regulation of endochondral ossification. Evidence for possible roles of the C-type natriuretic peptide/guanylyl cyclase-B pathway. J Biol Chem 273:11695-11700

9. Chusho H, Tamura N, Ogawa Y, Yasoda A, Suda M, Miyazawa T, Nakamura K, Nakao K, Kurihara T, Komatsu Y, Itoh H, Tanaka K, Saito Y, Katsuki M, Nakao K 2001 Dwarfism and early death in mice lacking C-type natriuretic peptide. Proc Natl Acad Sci USA 98:4016-4021

10. Bartels CF, Bukulmez H, Padayatti P, Rhee DK, van Ravenswaaij-Art C, Pauli RM, Mundlos S, Chitayat D, Shih L, Al-Gazali LI, Kant S, Cole T, Morton J, CormierDaire V, Faivre L, Lees M, Kirk J, Mortier GR, Leroy J, Zabel B, Kim CA, Crow Y, Braverman NE, van der Akker F, Warman ML 2004 Mutations in the transmembrane natriuretic peptide receptor NPR-B impair skeletal growth and cause acromesomelic dysplasia, type Maroteaux. Am J Hum Genet 75:27-34

11. Sundsfjord JA, Thibault G, Larochelle P, Cantin M 1988 Identification and plasma concentrations of the N-terminal fragment of proatrial natriuretic factor in man. J Clin Endocrinol Metab 66:605-610

12. Hunt PJ, Yandle TG, Nicholls MG, Richards AM, Espiner EA 1995 The aminoterminal portion of pro-brain natriuretic peptide (Pro-BNP) circulates in human plasma. Biochem Biophys Res Commun 214:1175-1183

13. Prickett TC, Yandle TG, Nicholls MG, Espiner EA, Richards AM 2001 Identification of amino-terminal pro-C-type natriuretic peptide in human plasma. Biochem Biophys Res Commun 286:513-517

14. Yandle TG, Fisher S, Charles C, Espiner EA, Richards AM 1993 The ovine hypothalamus and pituitary have markedly different distributions of C-type natriuretic peptide forms. Peptides 14:713-716

15. Komatsu Y, Chusho H, Tamura N, Yasoda A, Miyazawa T, Suda M, Miura M, Ogawa Y, Nakao K 2002 Significance of C-type natriuretic peptide (CNP) in endochondral ossification: analysis of CNP knockout mice. J Bone Miner Metab 20:331-336

16. Wright SP, Prickett TC, Doughty RN, Frampton C, Gamble GD, Yandle TG, Sharpe N, Richards M 2004 Amino-terminal pro-C-type natriuretic peptide in heart failure. Hypertension 43:94-100

17. Wu C, Wu F, Pan J, Morser J, Wu Q 2003 Furin-mediated processing of Pro-C-type natriuretic peptide. J Biol Chem 278:25847-25852

18. Yandle TG 1994 Biochemistry of natriuretic peptides. J Intern Med 235:561-576

19. Yamashita Y, Takeshige K, Inoue A, Hirose S, Takamori A, Hagiwara H 2000 Concentration of mRNA for the natriuretic peptide receptor-C in hypertrophic chondrocytes of the fetal mouse tibia. J Biochem (Tokyo) 127:177-179 
20. Sales N, Dutriez I, Maziere B, Ottaviani M, Roques BP 1991 Neutral endopeptidase 24.11 in rat peripheral tissues: comparative localization by 'ex vivo' and 'in vitro' autoradiography. Regul Pept 33:209-222

21. Kojima M, Minamino N, Kangawa K, Matsuo H 1990 Cloning and sequence analysis of a cDNA encoding a precursor for rat C-type natriuretic peptide (CNP). FEBS Lett 276:209-213

22. Suga S, Nakao K, Itoh H, Komatsu Y, Ogawa Y, Hama N, Imura H 1992 Endothelial production of C-type natriuretic peptide and its marked augmentation by transforming growth factor-beta. Possible existence of "vascular natriuretic peptide system." J Clin Invest 90:1145-1149

23. Minamino N, Aburaya M, Kojima M, Miyamoto K, Kangawa K, Matsuo H 1993 Distribution of C-type natriuretic peptide and its messenger RNA in rat central nervous system and peripheral tissue. Biochem Biophys Res Commun 197:326-335

24. Cameron VA, Aitken GD, Ellmers LJ, Kennedy MA, Espiner EA 1996 The sites of gene expression of atrial, brain, and C-type natriuretic peptides in mouse fetal development: temporal changes in embryos and placenta. Endocrinology 137:817-824

25. Prickett TC, Kaaja RJ, Nicholls MG, Espiner EA, Richards AM, Yandle TG 2004 $\mathrm{N}$-terminal pro-C-type natriuretic peptide, but not $\mathrm{C}$-type natriuretic peptide, is greatly elevated in the fetal circulation. Clin Sci (Lond) 106:535-540

26. Deloof S, Van Camp G, Chatelain A 1995 Absence of transplacental transfer of atrial natriuretic peptide in the rat: direct experimental evidence. Med Sci Res 23:347-349

27. Byers S, Moore AJ, Byard RW, Fazzalari NL 2000 Quantitative histomorphometric analysis of the human growth plate from birth to adolescence. Bone 27:495-501

28. Wang TJ, Larson MG, Levy D, Leip EP, Benjamin EJ, Wilson PW, Sutherland P, Omland T, Vasan RS 2002 Impact of age and sex on plasma natriuretic peptide levels in healthy adults. Am J Cardiol 90:254-258

29. Seibold-Weiger K, Wollmann HA, Ranke MB, Speer CP 2000 Plasma concentrations of the carboxyterminal propeptide of type I procollagen (PICP) in preterm neonates from birth to term. Pediatr Res 48:104-108

30. Kajantie E, Hytinantti T, Koistinen R, Risteli J, Rutanen EM, Seppala M, Andersson S 2001 Markers of type I and type III collagen turnover, insulin-like growth factors, and their binding proteins in cord plasma of small premature infants: relationships with fetal growth, gestational age, preeclampsia, and antenatal glucocorticoid treatment. Pediatr Res 49:481-489

31. Javaid MK, Godfrey KM, Taylor P, Shore SR, Breier B, Arden NK, Cooper C 2004 Umbilical venous IGF-1 concentration, neonatal bone mass, and body composition. J Bone Miner Res 19:56-63

32. Javaid MK, Taylor P, Shore SR, Gale C, Callagham FO, Godfrey KM, Cooper C 2003 Umbilical vein calcium concentration and maternal vitamin $\mathrm{D}$ status predict the mass of children at age nine years. Osteoporos Int 14(Suppl 1):S13
33. Siebler T, Robson H, Shalet SM, Williams GR 2002 Dexamethasone inhibits and thyroid hormone promotes differentiation of mouse chondrogenic ATDC5 cells. Bone 31:457-464

34. Ballock RT, O'Keefe RJ 2003 The biology of the growth plate. J Bone Joint Surg 85:715-726

35. Mushtaq T, Bijman P, Ahmed SF, Farquharson C 2004 Insulin-like growth factor-I augments chondrocyte hypertrophy and reverses glucocorticoid-mediated growth retardation in fetal mice metatarsal cultures. Endocrinology 145:2478-2486

36. Tawaragi Y, Fuchimura K, Tanaka S, Minamino N, Kangawa K, Matsuo H 1991 Gene and precursor structures of human C-type natriuretic peptide. Biochem Biophys Res Commun 175:645-651

37. Miyazaki Y, Tsukazaki T, Hirota Y, Yonekura A, Osaki M, Shindo H, Yamashita S 2000 Dexamethasone inhibition of TGF beta-induced cell growth and type II collagen mRNA expression through ERK-integrated AP-1 activity in cultured rat articular chondrocytes. Osteoarthritis Cartilage 8:378-385

38. Ohta S, Shimekake Y, Nagata K 1996 Molecular cloning and characterization of a transcription factor for the C-type natriuretic peptide gene promoter. Eur J Biochem 242:460-466

39. Danielpour D, Kim KY, Winokur TS, Sporn MB 1991 Differential regulation of the expression of transforming growth factor-beta s 1 and 2 by retinoic acid, epidermal growth factor, and dexamethasone in NRK-49F and A549 cells. J Cell Physiol 148:235-244

40. Potchinsky M, Nugent P, Lafferty C, Greene RM 1996 Effects of dexamethasone on the expression of transforming growth factor-beta in mouse embryonic palatal mesenchymal cells. J Cell Physiol 166:380-386

41. Chikuda H, Kugimiya F, Hoshi K, Ikeda T, Ogasawara T, Shimoaka T, Kawano H, Kamekura S, Tsuchida A, Yokoi N, Nakamura K, Komeda K, Chung UI, Kawaguchi H 2004 Cyclic GMP-dependent protein kinase II is a molecular switch from proliferation to hypertrophic differentiation of chondrocytes. Genes Dev $18: 2418-2429$

42. Yasoda A, Komatsu Y, Chusho H, Miyazawa T, Ozasa A, Miura M, Kurihara T, Rogi T, Tanaka S, Suda M, Tamura N, Ogawa Y, Nakao K 2004 Overexpression of CNP in chondrocytes rescues achondroplasia through a MAPK-dependent pathway. Nat Med 10:80-86

43. Komatsu Y, Itoh H, Suga S, Igaki T, Ogawa Y, Kishimoto I, Nakagawa O, Yoshimasa T, Nakao K 1996 Regulation of secretion and clearance of C-type natriuretic peptide in the interaction of vascular endothelial cells and smooth muscle cells. J Hypertens 14:585-592

44. Robson H, Anderson E, Eden OB, Isaksson O, Shalet S 1998 Chemotherapeutic agents used in the treatment of childhood malignancies have direct effects on growth plate chondrocyte proliferation. J Endocrinol 157:225-235 